\section{A criança com tuberculose: situações e interações no contexto da saúde da família}

\author{
Children with tuberculosis: situations and \\ interactions in family health care
}

\author{
Niños con cuadro de tuberculosis y las \\ interacciones en el contexto de la \\ salud de la familia
}

Danielle de Carvalho Machado 1 Martha Cristina Nunes Moreira 1 Clemax Couto Sant'Anna ${ }^{2}$

\section{Resumo}

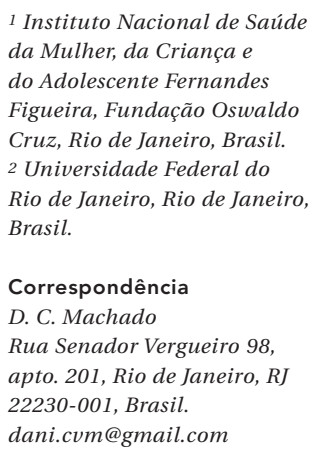

\section{Abstract}

This qualitative study analyzed meanings associated with tuberculosis (TB) in children. Interviews were conducted with lay caregivers and health professionals in six health situations in a vulnerable territory. Data collection was followed by thematic content analysis and interpretation in consultation with the literature concerning the concepts of stigma, childhood illness, and preservation of the façade. The results showed that the discussion on the meanings of $T B$ in children involves relativity of the core family concept and valuation of their network of relationships. The complexity of TB in children requires an expanded understanding of their health situation and interactions among the surrounding relationships. The health professional's role in identifying and managing possibilities for care and diagnostic and therapeutic difficulties is an important tool for health promotion in children.

Tuberculosis; Primary Health Care; Child; Family; Interpersonal Relations
Trata-se de uma pesquisa qualitativa que objetivou compreender os significados que envolvem o adoecimento por tuberculose (TB) na criança. Foram realizadas entrevistas com cuidadores leigos e profissionais em seis situações de saúde, num território de vulnerabilidade. Ao recolhimento dos dados, seguiu-se uma análise de conteúdo com identificação de categorias temáticas, e a interpretação dialogou com a literatura em conceitos como estigma, sentimento de infância, experiência de adoecimento e preservação da fachada. Os resultados demonstraram que a discussão sobre os significados de TB na criança passa pela relativização da noção de núcleo familiar e valorização de sua rede de relações. A complexidade do adoecimento infantil por $T B$ reclama uma compreensão ampliada de sua situação de saúde e das interações que permeiam as relações que se dão ao seu redor. O papel do profissional no reconhecimento e gerenciamento das possibilidades de cuidado e dificuldades diagnósticas e terapêuticas é importante ferramenta para a promoção da saúde na criança.

Tuberculose; Atenção Primária à Saúde; Criança; Família; Relações Interpessoais 


\section{Introdução}

A tuberculose (TB) permanece como um importante problema de saúde pública global, e a Organização Mundial da Saúde (OMS), em suas publicações, tem chamado atenção para a negligência crônica da doença na faixa pediátrica. Dificuldades de diagnóstico, situação socioeconômica desfavorável e precariedade de informação e de acesso a serviços de saúde são fatores que envolvem frequentemente a TB nessa faixa etária e colocam os sujeitos em situação de invisibilidade que não condiz com suas necessidades de cuidado 1,2 .

Sabe-se que a pobreza predispõe a doenças 3,4 e, embora a TB tenha diagnóstico e tratamento conhecidos há tempos 5 , sua persistência em bolsões de miséria ao redor do mundo aponta para o fato de que há outros determinantes, além dos biológicos, que também necessitam ser considerados 4,6. Dentre as necessidades de pesquisa nesse campo, encontram-se aquelas direcionadas aos significados que envolvem o adoecimento por TB na infância e a rede de relações que as envolve 7 .

Características específicas da faixa etária pediátrica a distinguem das outras e a colocam numa posição de vulnerabilidade e dependência $6,7,8$. Por isso, essa situação, pode traduzir-se em formas diferentes de interação, seja na circunscrição familiar, seja na relação com o serviço de saúde ou vizinhança, no tocante ao reconhecimento da TB no indivíduo.

Poucos estudos lançam luzes sobre as nuances que a doença assume na infância. Um dos raros encontrados estudou, em um sanatório na Cidade do Cabo, Africa do Sul, narrativas tanto de crianças internadas com TB, quanto de profissionais e familiares dos pacientes, discutindo a experiência do adoecimento que leva a isolamento, considerando sua condição de dependente6. Outros estudos, por sua vez, abordam a questão do adoecimento na infância a partir de outras condições de saúde, como asma, fibrose cística 7 e HIV 9, ressaltando, de forma semelhante, a importância da abordagem dos cuidadores em cada contexto.

A pesquisa que subsidia este artigo buscou analisar os significados que envolvem a TB em crianças. Pressupõe-se que o cuidado da TB na infância está submetido às interpretações do adulto de referência e que, nesse campo, pelo fato de ser uma doença infecciosa, de cuidado prolongado, seu tratamento estaria mediado por significados sobre cronicidade. Buscou-se, portanto, estudar os significados que cuidadores leigos e profissionais de crianças com diagnóstico de TB atribuem a esse adoecimento. O presen- te artigo trata da primeira parte dos resultados dessa pesquisa.

\section{Quadro teórico}

Como base teórica para a realização da pesquisa, foi acessada a literatura relacionada à situação da criança na saúde a partir da retomada do seu lugar na família, à atenção sobre seus cuidados e à determinação da pobreza nesse contexto. Esses três aspectos foram associados às análises sobre as representações culturais da TB ao longo dos anos que apontam para seu estigma 5,10,11. Entendemos a criança como sujeito, e a infância como um processo social 12,13,14,15.

As pessoas, incluindo as crianças, possuem uma dimensão identitária e experiencial que ultrapassa sua individualidade 16 . A família e o parentesco, ancorados na base naturalista da descendência pai e mãe, são o núcleo frequentemente pensado para a vivência dessa dimensão. Entretanto, consideramos que "família" não se restringe às referências de cossanguineidade; pelo contrário, “à trama que envolve os sujeitos na sua socialização primária costuma-se chamar família" ${ }^{16}$, não importando os arranjos por meio dos quais se organiza 17. Essa perspectiva traduziria menos, em tese, uma ação sobre indivíduos, ganhando maior força nas relações 18 .

Segundo Herzlich \& Adam 19, todo acontecimento importante da vida humana requer uma explicação, e a doença não escapa a esta exigência. Certamente, o significado que o cuidador de referência atribui ao adoecimento da criança com TB tem implicações tanto em seu tratamento, quanto na forma como serão administrados os cuidados, incluindo fatores como pré-diagnóstico. Esses significados surgem da interação dos sujeitos com o ambiente exterior no qual se encontram os profissionais de saúde, a quem também se pode atribuir influência sobre a elaboração simbólica dos cuidadores leigos 7 . Entendemos como cuidador leigo aquele indivíduo de referência para o cuidado da criança, familiar ou não.

Não é novidade, na literatura, que a pobreza mundial é potencialmente discriminatória em relação às mulheres e às crianças, sendo estas últimas mais vulneráveis aos seus efeitos 20,21,22. A situação de pobreza condiciona muitas das decisões ou condutas em torno do cuidado, alimentação e higiene num cenário de carência socioeconômica 23 . Se, por um lado, um indivíduo pobre não possui assegurado o cuidado à saúde, por outro, as crianças também não o possuem, por suas características de dependência de um cuidador que lhes interprete os sintomas e as reconheça como doen- 
tes. Quando as duas situações, de pobreza e de infância, convergem, podem-se somar as dificuldades, inclusive.

Aqui se entrelaça o significado que o familiar cuidador responsável atribui à doença e ao adoecimento da criança, seja qual for a causa, cujas raízes podem ser culturais, históricas, religiosas etc., com as necessidades de cuidado identificadas, as possibilidades de acesso a serviços de saúde e presença de redes de apoio e as decisões sobre que ações serão realizadas. Pode-se dizer, portanto, que o cuidador leigo é um intermediário entre a infância e os serviços de saúde. Sem que ele perceba o adoecimento da criança ou sem optar por procurar esses serviços, não é possível o estabelecimento de um vínculo criança-serviço.

Esse aporte contextual dialogou com o interacionismo simbólico de Goffman 24,25 e sua obra sobre rituais de interação, para a interpretação dos dados advindos da pesquisa. O uso dessa obra objetiva apontar a forma como um sujeito relaciona, no seu círculo social, os códigos sociais e a sua imagem, a fim de entrar numa situação e sustentar a sua identidade. Desses rituais de interação, fazem parte as mediações produzidas pelos estigmas da doença 25 .

\section{Materiais e método}

A pesquisa desenvolveu-se em um complexo de favelas situadas no Rio de Janeiro, Brasil. No município, a taxa de incidência de TB no ano de 2012 foi de 96.9 por 100 mil habitantes, sendo uma das mais altas do país. O complexo, composto por 13 favelas, apresentava um dos piores Índices de Desenvolvimento Humano (IDH) da cidade e tinha elevadas taxas de incidência da doença. Com um IDH de 0,72, ocupava, no ano 2000, a posição de número 123, num total de 126 bairros na cidade em relação ao índice 26 . Algumas características da comunidade eram a cobertura de $100 \%$ pela Estratégia Saúde da Família (ESF), o suporte do Núcleo de Apoio à Saúde da Família (NASF), oferecendo desde pediatras aos profissionais generalistas, e o fato de se tratar de um campo para práticas de ensino.

O presente estudo foi aprovado pelo comitê de ética em pesquisa do Instituto Nacional de Saúde da Mulher, da Criança e do Adolescente Fernandes Figueira, Fundação Oswaldo Cruz (IFF/Fiocruz), tendo sido realizado no ano de 2013. Foram realizadas entrevistas semiestruturadas, diário de campo e consulta a registros e prontuários, a fim de compor uma etnografia. Este artigo trata de uma parte dos resultados dessa pesquisa.
A fase de campo da pesquisa teve duração de três meses. Inicialmente, promoveu-se ambiência no local com o objetivo de se entender a organização do serviço e rotina dos profissionais. A seguir, realizou-se consulta aos registros dos casos de TB em crianças com 10 anos ou menos, notificados pelas unidades; contudo, nenhum caso havia sido notificado em 2012. Partiuse, então, para as notificações do ano de 2011 encontrando-se registro de três casos nos livros. Foi selecionado pelo menos um profissional que tivesse cuidado da criança, além de um cuidador leigo, e estes foram convidados a conceder entrevista gravada em dispositivo de áudio, após aceitação do termo de consentimento livre e esclarecido. A partir desses casos iniciais, por indicação dos cuidadores, outros casos não notificados ou ocorridos em outros anos foram incluídos na pesquisa, dentro do tempo estipulado para a realização do trabalho de campo. Ressaltamos que a entrada para as entrevistas em campo sempre foi apoiada por pelo menos um membro da equipe de saúde da família de referência, juntamente com a pesquisadora principal.

Os critérios de inclusão no estudo foram os seguintes: ter cuidado de criança com diagnóstico de TB, independentemente da localização corporal da doença. O cuidado foi comprovado por notificação no livro verde, ou por relato do profissional assistente quando a confirmação se deu pelas informações obtidas durante as entrevistas e consulta ao prontuário. Os critérios de exclusão foram os seguintes: não realização da entrevista de pelo menos um cuidador; não confirmação do diagnóstico de TB, seja pelo livro verde, seja pela memória dos profissionais ou pela consulta ao prontuário, seja pela impossibilidade de localização da família no território. Dessa forma, foram entrevistados, para cada criança com diagnóstico de TB, dois cuidadores, um profissional e outro leigo, exceto em uma das situações de saúde, em que foi entrevistado apenas o cuidador profissional, por dificuldade de acesso ao cuidador leigo.

Após a realização das entrevistas, estas foram transcritas, digitadas e salvas em formato de texto, os quais foram lidos por dois dos pesquisadores; depois dessa primeira leitura, foram destacadas as falas dos sujeitos da pesquisa que remetessem a algum dos objetivos do estudo. Em seguida, foram elaborados dois quadros, um para profissionais e outro para familiares: na primeira coluna do quadro, estavam distribuídos os casos; na primeira linha, os objetivos. Estabeleceu-se, assim, correspondência entre expressões e trechos das entrevistas e os objetivos da pesquisa, de forma a gerar um quadro analítico, que permitisse a interpretação à luz do 
quadro teórico, buscando outras literaturas para os achados.

Seguindo-se à elaboração dos quadros, foi realizada uma segunda leitura com o propósito de classificar, em categorias temáticas, as falas dos sujeitos, suas expressões significativas. A ação de reunir as expressões e falas em categorias de significados resultou na construção de três núcleos temáticos, porém, para fins deste artigo, apresentamos somente um: Saúde da Família e o cuidado da criança com TB: situações e rituais de interação. Exemplos de como foi articulada a correlação entre as falas, categorias analíticas e os núcleos temáticos podem ser visualizados na Tabela 1.

Com a realização de entrevistas a cinco familiares e sete profissionais, foram encontradas seis situações de saúde. Destas, duas não haviam

Tabela 1

Correlação entre as falas, categorias analíticas e os núcleos temáticos.

Expressões/Frases significativas/Explicações dos sujeitos

“Eu parei com tudo, parei com a minha vida pra cuidar da Lílian (...) tirei ela da escola, ela ficou um ano sem estudar (...) Falei: 'não, ela não vai pra escola não', porque na escola tem muita rejeição."

"Quando ela pegava assim aquela pilha de remédio pra tomar, eu falava: 'Poxa, gente, não podia ser eu? Já tô cascuda' (...) Eu pensava: 'Já tô cascuda (...), então eu aceito.' Agora, nossos filhos, a menina com 10 anos. Os dentes dela...".

"Ao mesmo tempo que é fácil é difícil, porque eu sou mãe né, então, assim, é... você se coloca no lugar de mãe".

"Como ela era de creche, então como é... a criança de creche tem muita a imunidade baixa né (...) vive com nariz escorrendo (...) ainda mais que ela é alérgica (...), tratava mas não resolvia, porque ela é alérgica".

"O que era difícil (...) era desconstruir da família de que... a preocupação excessiva que eles tinham, o cuidado, a proteção excessiva que eles tinham às vezes quando o caso já tava indo bem".

"É muito mais comum a gente tratar adulto do que criança. Então, a dificuldade de ser uma coisa que não tá muito no seu dia a dia, né".

"Eu tentei levar como o lado de profissional de ter que dar o medicamento pra ela ficar curada, mas também com meu lado de mãe né, convencendo ela com jeitinho".

"É muito complicado de tomar, vomitar, voltar, chorar... que faz parte da, da... criança mesmo, né".

"Não, ficou tranquilo. Tem nada de discriminação não".

"Entreguei na mão de Deus porque eu precisava trabalhar, então... entreguei".

"Tinha gente que é, me doía porque as vezes quando eu falava com as pessoas, as pessoas já tratava ela meio um pouco... aí eu que me... (...) aí eu já num gostava". "Ela tava normal, porque quando eu vejo que os meninos aqui em casa tá doente, é igual ao pai deles, eles já tão nas últimas, porque eles não fala".

"Na família que era muito menos protetora, a dificuldade era de tentar envolver a família no tratamento mesmo, né? Era de tentar fazer a família enxergar que sem os cuidados que a criança podia piorar".

"Eu só impliquei porque eles tipo falaram que iam prender minha filha no conselho tutelar (...). Não, se vai botar no conselho tutelar, vai botar pelo direito, eu não venho mais no médico' Eu não voltei mais, até hoje".

"Na compreensão deles é quase como se fosse assim: 'Ah, eu vou tomar uma dipirona porque eu tô com dor' (...). Eles tão ali no presente, eles não tão pensando tanto no futuro".

"Ele não fala pras pessoas que ele teve tuberculose e que a menina teve tuberculose. Tanto que eles não tiraram a menina da escola, ele mesmo que leva, ele que busca. Entendeu?".

\author{
Apresentação pública \\ Território de \\ Vulnerabilidade \\ Estigma
}

Núcleos temáticos

gerados

Saúde da família e o cuidado da criança com tuberculose: situações e rituais de interação 
sido notificadas, e outras duas, também não notificadas, foram lembradas pelos profissionais, mas não foram incluídas na presente pesquisa em virtude da dificuldade de acesso aos cuidadores. A única situação em que o familiar não foi entrevistado foi a situação 6 , pois, apesar de diversas tentativas, não se conseguiu contato com o cuidador leigo até o término da pesquisa. Nomes fictícios foram adotados, e as categorias profissionais foram omitidas, a fim de se preservar a identidade dos participantes.

A escolha por falar de situações de saúde e não de casos com diagnóstico de TB se deu em decorrência do diálogo com a perspectiva teórica na qual ancoramos a pesquisa: o interacionismo simbólico. Aqui, fez-se central a ideia das situações sociais como organizadoras da experiência, evocando relações, pertencimento, interpretações e construção identitária, além da busca da desconstrução da noção de caso com enfoque biomédico, em que a doença como entidade é central.

\section{Resultados e discussão}

Dentre as situações de saúde encontradas nas entrevistas, ganharam destaque quatro situações emblemáticas, no que diz respeito às expressões possíveis do campo de interações referidas, como ter um filho com TB ou ser um profissional envolvido nesse universo. Assim, interpretamos dois campos de respostas relativas aos comportamentos das famílias e reação dos profissionais quanto a essas respostas: autonomia e proteção, em pares contrastivos, onde convivia a tensão entre menos autonomia/mais autonomia, menos proteção/mais proteção.

Autonomia foi entendida não como a capacidade de determinação do paciente ou do cuidador, mas o fortalecimento das relações entre os pacientes, familiares e profissionais, de forma que se possibilitasse o gerenciamento satisfatório da gestão das suas redes de dependência, e não de um ideal ficcional de independência impossível 26,27. O termo proteção foi adotado como compreendido pela doutrina da proteção integral da criança, consagrada pelo Estatuto da Criança e do Adolescente (ECA) 28. Esta doutrina compreende que as normas que cuidam de crianças e adolescentes devem concebê-los como cidadãos plenos, porém sujeitos à proteção prioritária, tendo em vista que são pessoas em desenvolvimento físico, mental, moral, espiritual e social.

Portanto, classificamos as situações da seguinte forma: situação 1 - menos autônoma; situação 2 - mais autônoma; situação 3 - menos protetora; situação 4 - mais protetora. As situações de saúde descritas não objetivam a exaustão dos comportamentos relacionais possíveis entre famílias e profissionais; na verdade, nos aspectos em que tocam, visam a ser representativas de um padrão de comportamento passível de exemplificar respostas possíveis e referidas aos rituais de interação entre familiares que cuidam de crianças com TB, sabendo que eles mesmos estão sujeitos a serem avaliados por profissionais de saúde quanto às suas atitudes de cuidado 24 .

A Tabela 2 resume as situações e as características que nos levaram a classificar cada uma conforme os parâmetros de autonomia e proteção, a fim de mais claramente exemplificar essa interpretação.

A situação 1 envolveu o caso de uma família pertencente a uma determinada área da ESF, em que o pai (José) e uma das filhas foram diagnosticados com TB. Em algum momento, foi abandonado o tratamento; posteriormente, houve mudança de área, modificando a equipe responsável pela família. Segundo a profissional entrevistada, não houve qualquer tipo de informação de uma equipe para a outra acerca da situação da família. O diagnóstico de TB e a descoberta de que estavam sem tratamento foi verificado durante uma visita domiciliar. Depois de realizados novos testes e confirmados os dois diagnósticos, iniciou-se o tratamento supervisionado nos dois familiares com TB, até completarem-se os seis meses. José afirmou, durante a entrevista, que não percebeu os sintomas como problema que justificasse procurar atendimento para ele e para a filha, seja no primeiro diagnóstico, seja depois que mudou de equipe. A interpretação da postura de passividade e dependência em face dos sintomas e diagnóstico de TB advém do acesso a determinadas expressões êmicas, construídas pelos sujeitos, relativas à ideia de que o conhecimento técnico conduz e, mais do que isto, determina a busca de cuidado:

“Se não fosse eles, né? A gente ficava perdido. Não sabia nem o que fazer direito. Ah, que eles chegaram aqui e mandou logo fazer o exame. A eu tive que correr rápido, porque eu não sabia direito como é que era isso [...] pra mim eu tava tranquilo, inclusive eu vou lá amanhã pra fazer outro... porque vieram duas aí, aí mandaram eu ir lá que eu tô tossindo" (José, pai).

Mesmo sabendo do diagnóstico, nem José nem sua esposa, os adultos da residência, procuraram a equipe para buscar tratamento. As queixas foram referidas somente na visita domiciliar, quando a equipe de saúde da família percebeu que poderia haver algo de anormal, assumindo o caso com a realização do tratamento supervisionado. 
Tabela 2

Situações conforme pares contrastivos em relação à autonomia e proteção.

\begin{tabular}{|c|c|c|c|c|}
\hline $\begin{array}{l}\text { Situação de } \\
\text { família }\end{array}$ & $\begin{array}{l}\text { Cuidador } \\
\text { familiar }\end{array}$ & $\begin{array}{c}\text { Criança com diagnóstico de } \\
\text { tuberculose }\end{array}$ & Classificação & Parâmetros \\
\hline \multirow[t]{3}{*}{1} & José & Aline & Menos autônoma & - Não reconhece sintomas \\
\hline & & & & - Não utiliza serviço de saúde para diagnóstico \\
\hline & & & & - Depende da busca ativa do profissional \\
\hline \multirow[t]{5}{*}{2} & Débora & Cássia & Mais autônoma & - Apresenta explicações para os sintomas \\
\hline & & & & - Utiliza outros serviços de saúde para diagnóstico e \\
\hline & & IVIIena & & tratamento, que não o ESF \\
\hline & & & & - Cria redes sociais \\
\hline & & & & - Apropria-se de discurso técnico \\
\hline \multirow[t]{5}{*}{3} & Maria & Laila & Menos protetora & - Inicia e interrompe tratamento orientado pelos \\
\hline & & & & profissionais mais de uma vez \\
\hline & & Elias & & - Não leva a criança para consultas \\
\hline & & & & - Não trata de si mesma \\
\hline & & & & - Profissionais tentam acionar conselho tutelar \\
\hline \multirow[t]{6}{*}{4} & Gracy & Lílian & Mais protetora & - Retira a criança da escola por período prolongado \\
\hline & & & & $(1$ ano $)$ \\
\hline & & & & - Retira a criança do convívio com a vizinhança \\
\hline & & & & - Coloca a criança para dormir no mesmo quarto, em \\
\hline & & & & sistema de vigilância \\
\hline & & & & - Preocupa-se com estigma \\
\hline \multirow[t]{2}{*}{5} & Hilda & Cecília & & Não foram classificadas conforme \\
\hline & & & & esses parâmetros \\
\hline 6 & - & Mário & & \\
\hline
\end{tabular}

ESF: Estratégia Saúde da Família.

A visão do profissional sobre este caso aproxima-se do que Sarti 18 (p. 98) comenta a respeito do entendimento de família no ESF: “ $A$ abordagem familiar, preconizada no modelo do ESF, acaba sendo traduzida em uma forma de tratamento que consiste em tratar o usuário 'como se fosse da família', em uma projeção da ideia de família dos profissionais (técnicos e agentes comunitários), com base na lógica da esfera privada da família, que [...] é uma referência simbólica fundamental no mundo dos pobres (mas não só nele!), para se pensar o mundo social como um todo, indiferenciando as esferas pública e priva$d a$ ". Houve ainda um "abraço", ou acolhimento, a essa família e até mesmo uma identificação emocional:

“O papel do profissional é o primórdio de tudo, porque é ele quem vai diagnosticar, é ele quem vai inserir o medicamento. [...] Ele vai cuidar da parte da saúde e, assim, o que não impede também da parte afetiva, porque ele acaba criando um vínculo com aquela criança. Ao mesmo tempo que é fácil, é difícil, porque eu sou mãe, né? Então, assim, é... você se coloca no lugar de mãe" (Ana, profissional de saúde).

Há também uma aceitação de que o profissional é o responsável, e a família é a dependente (não somente a criança, mas também os cuidadores leigos), numa relação vertical:

"Ela [a criança] não entende nem o que é tuberculose [...] deve ser muito difícil pra uma criança assimilar. [...] O trabalho do profissional é essencial. Se o profissional não atuar, a família, mesmo tendo o entendimento, não tem como realizar todo o tratamento sozinha, tem que ter o apoio do profissional. Então, assim, eu tratava ele como uma criança grande" (Ana, profissional de saúde).

A situação 2 envolveu uma família em que a principal cuidadora era a avó (Débora), que foi a entrevistada. Foram dois casos em crianças e mais dois em adolescentes, estes com diagnóstico de TB multirresistente, possivelmente os casos-índice; um deles era o namorado da mãe das 
crianças e foi a óbito pela TB. O diagnóstico dos adolescentes já havia sido feito no momento em que as duas crianças desenvolveram a doença, o que indicava um conhecimento prévio sobre o que envolvia seu tratamento. A avó, pelo cuidado anterior dispensado aos adolescentes, construiu uma rede de relacionamentos que influenciou na forma de responder ao adoecimento das duas crianças. Os adolescentes haviam sido tratados em um centro de referência para TB, em virtude do diagnóstico de TB multirresistente. Quando a primeira criança adoeceu, inicialmente a investigação foi conduzida pela equipe de saúde da família que suspeitou de TB, porém a explicação da avó para o adoecimento da criança era diversa: “Como ela era de creche, então como é... a criança de creche tem muita a imunidade baixa, né? [...] vive com nariz escorrendo, ainda mais que ela é alérgica, tratava, mas não resolvia, porque ela é alérgica" (Débora, avó).

Débora aceitou o início do tratamento na clínica, todavia, como não acreditava no diagnóstico, percorreu vias alternativas para confirmar suas suspeitas. Acionou sua rede de relacionamentos no centro de referência, onde conseguiu ser atendida e, após cerca de três meses de tratamento, realizar uma broncoscopia. Uma vez que o resultado do exame foi negativo, a avó, acreditando que a criança não tinha TB, abandonou o tratamento. Explicação esta diversa da apresentada pelo profissional entrevistado sobre tal situação de saúde, que, adicionalmente, tinha formação em pneumologia pediátrica e experiência de longa data em tratamento de crianças com TB: "Eu custo a acreditar que não seja tuberculose, gente"; "E a broncoscopia não ia dar mais nada, né gente? Quatro meses...” (Marcela, profissional de saúde).

Quando, posteriormente, a outra criança, irmã da primeira, adoeceu, apresentando adenomegalia, Débora percorreu os serviços da UPA (Unidade de Pronto Atendimento) e da Clínica da Família, mas, a princípio, não se suspeitou de TB. Por causa de uma experiência prévia de Débora com outra criança da comunidade com quadro semelhante e pela lembrança de casos vistos durante a internação dos adolescentes, ela acionou novamente a sua rede "extraclínica" e levou a neta diretamente ao centro de referência. Lá, diagnosticou-se TB ganglionar, sendo realizado o tratamento. A clínica da família não teve conhecimento do adoecimento desta última criança.

Patente neste caso é a apropriação, pela cuidadora leiga, da condução do itinerário das netas. A equipe de saúde da família é consultada e acionada na medida em que atende às suas expectativas, no entanto, da mesma forma, é facil- mente ignorada, quando deixa de atendê-las. O papel "secundário" da equipe do ESF neste caso, como compreendido pela cuidadora leiga, pode ser percebido em suas falas: "Aqui eles, eles tratavam, é... cuidavam na hora que já tava diagnosticado mesmo, que a menina teve. Então eles... assim, só isso"; "Como já tava acostumada lá..." (Débora, avó).

E ainda a percepção do seu próprio papel como responsável:

"Teve uma vez que a assistente social ligou pra mim e pediu que eu fosse internar ele, e só eu poderia fazer isso, porque ela achava que eu [...] não tinha medo, eu chegava e falava que tinha de fazer, falava e falo mesmo" (Débora, avó).

Apesar de reconhecida a importância do respeito à autonomia, da corresponsabilidade e capacidade do próprio sujeito para intervir sobre sua situação de saúde, como preconizado pela Política Nacional de Humanização 29, não raramente revela-se uma angústia do profissional diante da limitação da aplicação do seu saber. A esta angústia, soma-se o fato de o objeto do cuidado se tratar de uma criança, com necessidade permanente de avaliação do quão adequadamente o enfermo está sendo cuidado pelo familiar. Nesse contexto, as ações dos profissionais são conduzidas após os direitos concedidos ao cuidador leigo e a noção de responsabilidade do profissional sobre a criança terem sido pesados na balança.

Nesta segunda situação de saúde, não houve mais interferência dos profissionais quanto à condução do tratamento da criança em questão, diferentemente da próxima situação, em que a problemática da responsabilidade do profissional versus autonomia do cuidador leigo tornouse ainda mais evidente.

A situação 3 envolve uma família de muitos membros, conhecida por todas as equipes da clínica da família devido à dificuldade que apresentam para o cuidado. Trata-se de uma família itinerante, segundo a fala dos profissionais: " $E$ ai sai da área, volta pra área, e a gente não consegue fazer o tratamento" (Renato, profissional de saúde). Vários de seus membros tiveram diagnóstico de TB e se trataram diversas vezes, sem, no entanto, completar o tratamento. Muitos eram usuários de drogas, e pelo menos um tinha HIV. Em certa ocasião, uma criança de dois anos, irmã de outras seis, cuja mãe havia sido diagnosticada com TB pela terceira vez, foi investigada pela clínica e recebeu o mesmo diagnóstico. Contudo, pela dificuldade de adesão ao tratamento, aventou-se a possibilidade de acionar o conselho tutelar, na tentativa de garantir melhor cuidado a essa criança, o que gerou quebra de vínculo do serviço com a mãe e, consequentemente, com 
a criança. Apresentou-se, então, um quadro que refletia uma postura considerada negligente em relação à criança e que requereu, por isso, resposta dos profissionais no sentido de proteção a ela.

A situação 4 poderia ser chamada de oposta à anterior: trata-se de um casal e três filhos, moradores de uma casa, em cujo segundo andar residia a avó materna, que teve um diagnóstico de TB. Quando a avó terminou o tratamento, uma das crianças iniciou os sintomas. A mãe a levou, primeiramente, a um serviço privado ao notar o que nomeou de "convulsãozinha à toa" (a criança ficava pálida e vomitava uma "gosma", segundo afirmou). Naquele serviço, a criança foi encaminhada para um pneumologista pediátrico, que orientou fisioterapia e solicitou exames, incluindo escarro; o resultado, porém, foi negativo. Depois de algumas semanas sem resolutividade, o profissional do plano de saúde orientou a mãe a procurar um posto de saúde próximo de casa, onde, então, foi diagnosticada TB na criança. Segundo a descrição da situação pelo profissional e a própria fala da mãe, foi possível perceber a resposta da família como protetora, com adoção de medidas além daquelas orientadas para precaução e tratamento, consideradas até mesmo exageradas pelos profissionais de saúde:

"Eu vi como a família ficou abalada com o fato de receber a notícia de que a criança tinha tuberculose, de precisar fazer um tratamento de seis meses. O que era difícil [...] era desconstruir da família de que... a preocupação excessiva que eles tinham, o cuidado, a proteção excessiva que eles tinham às vezes, quando o caso já tava indo bem" (Renato, trabalhador de saúde).

"Eu parei com tudo, parei com a minha vida pra cuidar [...]. Parei com tudo, tirei ela da escola [...], ela ficou um ano sem estudar. Aí botei a cama dela ali, em frente à janela pra ela. Fica bem arejada. Aí ela ficou um ano, dormindo aqui no meu quarto" (Gracy, mãe).

Com a problematização desses casos e considerando as dificuldades apontadas pelos profissionais ao lidar com crianças com $\mathrm{TB}$, apresentou-se um quadro que, primeiramente, evidenciava uma certa ausência da criança com TB na atenção primária. Nenhum dos profissionais afirmou, apesar de alguns terem maior experiência no assunto, sentir-se seguro para fazer o diagnóstico; quanto ao tratamento, somente os pediatras não o colocaram como dificuldade percebida. A maioria deles nunca havia tido experiência prévia com esse diagnóstico em crianças, indicando que a TB na infância não assume o mesmo significado de prevalência da TB em adultos, o que acaba traduzindo o adoecimento por esta enfermidade na infância como algo raro e, portanto, "do especialista”. Mesmo os profissionais médicos de família, sejam residentes, sejam preceptores, expuseram suas dificuldades no trato com a criança e a necessidade de recorrer ao pediatra (especialista), pelas especificidades desse adoecimento: os protocolos de atendimento e manejo são diferentes daqueles dos adultos 2; os critérios para diagnósticos são outros, pois as crianças frequentemente têm dificuldade de produzir escarro e são paucibacilares; além disso, o tratamento exige adequações, e o seu acompanhamento, da mesma forma, apresenta nuances que requerem do profissional expertise e dedicação para um cuidado integral 2,30.

Se a "ausência" leva à falta de prática e a falta de prática, a uma dificuldade de manejo, é natural que se perceba que os profissionais enfrentam problemas para lidar com o tema de TB em crianças. Essa dificuldade foi relatada principalmente quanto ao diagnóstico, à administração de medicamentos, ao acompanhamento da evolução, a aspectos relacionados ao convívio em creche e à compreensão da doença ou falta desse entendimento pela criança.

A limitação de conhecimento e prática dos profissionais levava frequentemente à extrapolação do know-how científico do universo do adulto para o pediátrico, sem as devidas adequações às particularidades desses sujeitos. Muitas vezes, pelas dificuldades éticas ou operacionais em se realizarem pesquisas com a faixa etária infantil, lançar mão do conhecimento do adoecimento adulto torna-se a única alternativa para uma tentativa de manejo com crianças ${ }^{8}$. Em outras ocasiões, mesmo havendo protocolos e literatura disponíveis, estes podem não ser devidamente acessados; ademais, a falta de prática cotidiana pode acarretar insegurança, pela necessidade de se modificar o olhar do adoecimento adulto para o infantil.

Com base nesses quatro exemplos de situações de saúde que demonstram formas diferentes de relacionamento entre as famílias de crianças com TB e os serviços de atenção primária à saúde, é possível apreender a complexidade e não uniformidade quanto às possibilidades de compreensão da doença e interação entre os sujeitos. Segundo Castellanos, é importante estudar o processo do adoecimento crônico da criança, que envolve as instituições e as famílias, "compreendendo os sentidos produzidos nas interações sociais aí presentes, a partir das quais se define, também, o próprio sentido da cronicida$d e$ " 7. Loyola (1984, apud Maranhão \& Sarti 31), reflete que atitudes e reações nesse contexto são diversas, como diversos são os determinantes que os condicionam: "As famílias têm percepções e avaliações dos problemas de saúde das crianças 
com base em seus próprios modelos explicativos de doenças e sua terapêutica" 31 (p. 259).

Parte do comportamento adotado pode ser entendido se traçado paralelo com a formação de um sentimento de infância, como descrito por Ariès 12, e com a construção social da infância, reafirmada por diversos autores posteriormente 7,13,14,15. Estas formas de interação no que se refere à proteção traduzem o que já afirmava Castellanos 7 (p. 50): “a vulnerabilidade infantil define-se em relação ao desejo adulto, tanto aquele que visa seu dano moral ou físico quanto aquele que objetiva a sua proteção". Em comum, a vulnerabilidade da criança em relação à atuação do adulto pode ser percebida, seja pela maior proteção, como na situação 4, seja pela menor proteção, como no caso da situação 3 . Ainda, quanto às interações com os serviços de saúde nessas situações, é possível verificar que, nos conflitos, a percepção dos cuidadores profissionais sobre seu papel na atenção à criança abrange também a intervenção sobre os cuidadores leigos, por meio dos aconselhamentos, orientações e intervenções, como o acionamento do Conselho Tutelar. Destaca-se, assim, a perspectiva de que também os cuidadores leigos são foco de atuação dos profissionais de saúde, "uma vez que todos estão implicados no processo de saúde-doençacuidado" 7 (p. 51).

Pode-se dizer que o dimensionamento do problema de saúde das crianças relacionadas nas situações descritas, realizado pelos respectivos cuidadores leigos e interpretado conforme o comportamento destes em relação aos enfermos, tende a traduzir tanto a predisposição emocional do cuidador para com a criança, como uma atitude na direção da "preservação da fachada", como conceituado por Goffman 24. Segundo o autor, "a fachada é uma imagem do eu delineada em termos de atributos sociais aprovados" 24 (p. 14). O caráter estigmatizante da TB 5,10,11, bem como a cronicidade de cuidados exigida pela doença, interfere na resposta dos cuidadores leigos após a ruptura causada pelo diagnóstico, no sentido de adotarem estratégias para a reorganização do cotidiano, num processo de normalização 7,24. O "normal”, nesse caso, seria não ter TB, e a preservação da fachada se conduziria nesse sentido.

Na situação 4, a retirada do convívio habitual da criança, a colocação sob vigilância e a criação de um "esconderijo" compõem um "processo de evitação", que traduz a estratégia adotada para a preservação da fachada. Da mesma forma, nas situações 1 e 3, a negação dos sintomas, seja no caso da indiferença em relação a eles, seja no caso extremo da recusa do tratamento ou atribuição de cura da doença a divindades, também pode refletir a intenção da preservação dessa fachada em face da rede de relacionamentos com a vizinhança, pessoas da mesma religião e convivência. Na situação 2, por sua vez, acontecem tanto a negação, como a busca pelo tratamento. Interessante considerar, neste caso, que, independentemente do diagnóstico real, o que determinou a conduta da avó e o cuidado final prestado a cada criança foi a explicação que a cuidadora leiga deu para o adoecimento de cada uma delas. Para aquela assumida com TB, buscou-se tratamento; para aquela que a cuidadora não acreditava ser TB, buscou-se outra explicação para o adoecimento. Entretanto, também nessa situação, ambos os caminhos tomaram direção no sentido de preservação da fachada, da procura por resguardar outros aspectos da identidade que não se reduzissem à de doente.

A perspectiva dos rituais de interação foi tratada, na presente pesquisa, a partir da interpretação dos dados sobre essas situações de interação que se dão por intermédio de laços construídos por vizinhança, amizade e solidariedade. Tais situações são muito comuns em ambientes nos quais a pobreza desencadeia a construção de relações de sociabilidade.

\section{Considerações finais}

As dificuldades relatadas pelos profissionais de diagnóstico e manejo da TB em crianças a colocam, na prática, numa posição intermediária entre o especialista e a atenção básica. Permitem inferir um possível ciclo em que o pouco diagnóstico levaria à pouca suspeição e, ao mesmo tempo, também à pouca valorização da criança na investigação da rede de contatos.

Levar a sério a ideia de que não tratamos de casos de TB, mas de situações de saúde, ajudanos a compreender melhor o adoecimento por TB na infância, que envolve não somente o status biológico do corpo, mas as relações familiares com o serviço de saúde e com a comunidade, que contornam e desenham possibilidades de saúde e doença para cada criança. O caso clínico reduz à biologia, naturaliza, perde as noções de interação e relações em ambientes sociais ampliados, enquanto a noção de situação permite ancorar atores, contextos e necessidades.

Compreender os papéis dos envolvidos no adoecimento e as possibilidades diversas de interação, bem como o sentido de cronicidade da TB na infância, aparentes nessas interações a partir das estratégias necessárias para a preservação da fachada, permite-nos ter uma visão mais ampliada da condição de uma criança com a doença, vulnerável, por diversos ângulos, à atuação dos profissionais e familiares, assim como ao estigma 
da doença. Faz-se necessário, na atenção primária, um olhar atento a essa condição, com a compreensão da complexa rede de relacionamentos e possibilidades da criança, de forma que sejam garantidos diagnóstico e cuidado qualificado, adequado para cada situação que se apresente.

\section{Resumen}

Se trata de un estudio cualitativo que tuvo como objetivo comprender los significados que implica la tuberculosis (TB) en los niños. Se realizaron entrevistas con los cuidadores y los profesionales laicos en seis situaciones de salud en un territorio vulnerable. La recolección de datos fue seguida por un análisis de contenido para identificar los temas y la interpretación en la literatura sobre conceptos como el estigma, experiencia de la enfermedad y la preservación de la identidad. Los resultados mostraron que la discusión sobre los significados de TB en niños pasa por la relatividad del concepto de la base de la familia y la valoración de su red de relaciones. La complejidad del niño con cuadro de TB exige una comprensión más amplia de su situación de salud y las interacciones que permean las relaciones que se producen a su alrededor. El papel del profesional en el reconocimiento y manejo de las posibilidades de atención y dificultades diagnósticas y terapéuticas es una herramienta importante para la promoción de la salud en los niños.

Tuberculosis; Atención Primaria de Salud; Niño;

Familia; Relaciones Interpersonales
Um dos limites que deve ser assumido como desafio para futuras pesquisas refere-se ao próprio campo, exposto a situações de violência, vulnerabilidade de diversos níveis, que comprometem a segurança do pesquisador. Outro limite está relacionado à dificuldade no acesso aos dados que permitam a localização das crianças no território.

\section{Colaboradores}

D. C. Machado foi responsável pela pesquisa de campo que gerou a análise, a interpretação e escrita do artigo. M. C. N. Moreira colaborou no desenho metodológico, análise e interpretação dos achados, e revisão da versão final. C. C. Sant'Anna contribuiu na interpretação e revisão de dados, e na revisão da versão final.

\section{Agradecimentos}

À Coordenação de Aperfeiçoamento de Pessoal de Nível Superior, pela concessão de bolsa para mestrado acadêmico a um dos pesquisadores. 


\section{Referências}

1. Stop TB Partnership. No more crying, no more dying. Toward zero TB deaths in children. Geneva: World Health Organization/Stop TB Partnership; 2012.

2. World Health Organization. Guidance for national tuberculosis programmes on the management of tuberculosis in children. 2nd Ed. Geneva: World Health Organizations; 2014.

3. Costa Neto C. Tuberculose e miséria. Rio de Janeiro: Nova Razão Cultural; 2011.

4. Buss PM, Pellegrini Filho A. A saúde e seus determinantes sociais. Physis (Rio J.) 2007; 17:77-93.

5. Bertolli Filho C. História social da tuberculose e do tuberculoso: 1900-1950. Rio de Janeiro: Editora Fiocruz; 2001.

6. Abney K. At the foot of Table Mountain: paediatric tuberculosis patient experiences in a centrilized treatment facility in Cape Town, South Africa [Tese de Doutorado]. Cape Town: University of Cape Town; 2014.

7. Castellanos M. Adoecimento crônico infantil: um estudo das narrativas familiares. São Paulo: Editora Hucitec; 2011.

8. Moreira MEL, Goldani MZ. A criança é o pai do homem: novos desafios para a área de saúde da criança. Ciênc Saúde Coletiva 2010; 15:321-7.

9. Almeida JM, Praca NS. Transmisión vertical del VIH: comprendiendo el sentimiento de los padres por la técnica proyectiva. Index Enferm 2009; 18:80-4.

10. Santos WS. Representações sociais da tuberculose pulmonar [Dissertação de Mestrado]. Jequié: Universidade Estadual do Sudoeste da Bahia; 2010.

11. Pôrto A. Representações sociais da tuberculose: estigma e preconceito. Rev Saúde Pública 2007; 41(1 Suppl):43-9.

12. Ariès P. História social da criança e da família. Rio de Janeiro: Editora Guanabara Koogan; 1986.

13. Cohn C. Antropologia da criança. Rio de Janeiro: Jorge Zahar Editores; 2005.

14. Pires F. O que as crianças podem fazer pela antropologia? Horizontes Antropológicos 2010; 16:137-57.

15. Corsaro WA. Sociologia da infância. Porto Alegre: Editora Artmed; 2011

16. Duarte LFD. O sangue que nos faz. Ciência Hoje 2012. http://cienciahoje.uol.com.br/colunas/sen tidos-do-mundo/o-sangue-que-nos-faz (acessado em 05/Fev/2014).

17. Trad LAB, organizadora. Família contemporânea e saúde: significados, práticas e políticas públicas. Rio de Janeiro: Editora Fiocruz; 2010.

18. Sarti C. O lugar da família no Programa de Saúde da Família. In: Trad LAB, organizadora. Família contemporânea e saúde: significados, práticas e políticas públicas. Rio de Janeiro: Editora Fiocruz; 2010. p. 91-103.
19. Adam P, Herzlich C. Sociologia da doença e da medicina. Bauru: EDUSC; 2001.

20. Visão Mundial Brasil. Estudo sobre as políticas públicas de proteção à saúde infantil e materna no Brasil: um olhar especial para os filhos de mães adolescentes. http://www.andi.org.br/sites/ default/files/legislacao/estudo_politicas_publicas_protecao_saude_infantil.pdf (acessado em 20/Dez/2014).

21. Barros E. O gasto federal em saúde com crianças e adolescentes. In: Rocha PE, organizador. Políticas públicas sociais: um novo olhar sobre o orçamento da União, 1995/98. Brasília: Instituto de Estudos Socioeconômicos; 1999. p. 113-30.

22. Moreira MCN. Dimensões do associativismo voluntário no cenário das relações entre saúde, pobreza e doença. Ciênc Saúde Coletiva 2010; 15:917-24.

23. Bronfman M. Como se vive se muere. Buenos Aires: Lugar Editorial; 2001.

24. Goffman E. Ritual de interação: ensaios sobre o comportamento face a face. Petrópolis: Editora Vozes; 2011.

25. Goffman E. Estigma - notas sobre a manipulação da identidade deteriorada. Rio de Janeiro: Editora LTC; 1988.

26. Soares JCRS, Camargo Jr. KR. A autonomia do paciente no processo terapêutico como valor para a saúde. Interface Comun Saúde Educ 2007; 11:65-78.

27. Duarte MCSD, Moreira MCN. Autonomia e cuidado em terapia intensiva pediátrica: os paradoxos da prática. Interface Comun Saúde Educ 2011; 15:687-700.

28. Brasil. Lei no 8.069 de 13 de julho de 1990. Dispõe sobre o Estatuto da Criança e do Adolescente e dá outras providências. Diário Oficial da União 1990; 16 jul.

29. Secretaria de Atenção à Saúde, Ministério da Saúde. Política Nacional de Humanização da Saúde. Documento Base. 4a Ed. Brasília: Ministério da Saúde; 2007

30. Detjen A, Gnanashanmugam D, Talens A. A framework for integrating childhood tuberculosis into community-based child health care. Washington DC: CORE Group; 2013.

31. Maranhão DG, Sarti CA. Shared care: negotiations between families and professionals in a child day care center. Interface Comunic Saúde Educ 2007; 11:257-70.

Recebido em 29/Mai/2014

Versão final reapresentada em 13/Jan/2015

Aprovado em 14/Abr/2015 